\title{
BAT DIES ON BARBED WIRE FENCE
}

\section{ALLEN N. WISELY, 34 Fairfax Crescent, St. Albert, Alberta T8N 1 Y1}

On September 4, 1977, three others and I found the partly dehydrated body of a Hoary Bat, Lasiurus cinereus, hanging from a barbed wire fence separating two areas of grassland at the north side of Beaverhill Lake. The bat, an adult female, had been caught on a barb along the upper strand of the fence and had been unable to free itself. On closer examination, it was observed that the barb had penetrated its uropetagium (the membanous skin connecting the hind limbs and tail) on the left side, and the bat had twisted, tangling its left foot and further securing itself to the barb.

In Alberta the Hoary Bat is a summer resident in the forested regions, but is seldom seen and is regarded as scarce throughout its range in the Province ${ }^{1}$. The occurrence of this species in an open area of grassland is noteworthy. The nearest trees were aspens located approximately $250 \mathrm{~m}$ north.

Previous records of this type of mortality in Hoary Bats are known from Madison, Wisconsin and Collegeville, Minnesota. ${ }^{2}{ }^{3}$ In these cases and in others the bats were found on the upper strand of wire, and the uropetagium of each bat had been caught on a barb. ${ }^{4}$

The coincidence of this set of circumstances is remarkable and raises questions about the mechanics of the interaction of bats and barbed wire. Based on the two previously documented occurrences, Gillette and Kimbrough $^{4}$ suggested that Lasiurus might not be able to detect fences in time to avoid hitting them. ${ }^{5}$

It is possible that one or more of the following hypotheses may explain the phenomenon. One, the bats may have attempted to avoid the wire or slow their approach to it by drawing the uropetagium downward, thereby exposing it to the wire. Two, in the use of the uropetagium for catching and feeding on flying insects, the bats may have attempted to catch an insect near the fence and accidently swept this membrane on to the barb, or perhaps momentarily associated the shape of the barb with that of an insect and attempted to entrap it in the membrane. Three, the bats may have attempted to perch on the wire and caught this membrane on the barb while landing.

The results of tests that show that Lasiurus is a bat with a relatively fast and direct flight and observations that this bat shows less avoidance to mist nets than other species may lend credence to the first two hypotheses. ${ }^{64}$ However, a carefully controlled photographic study, coupled with biophysical or physiological evidence of this interaction, may be required before the cause of this phenomenon is understood.

I wish to thank Hugh C. Smith, Curator of Mammalogy for the Alberta Provincial Museum for information about the bat and his encouragement and comments on this paper.

'SOPER, J. D. 1964. The Mammals of Alberta. Hamley Press, Edmonton, Alberta

IIWEN, F. A. 1958. Hoary bat the victim of a barbed wire fence. J. Mammal. 39(3): 438.

${ }^{3}$ HIBBARD, E. A. 1963. Another hoary bat found hanging on a fence. J. Mammal. 44(2): 265.

${ }^{4}$ BARBOUR, R. B. and W. H. DAVIS. 1969 Bats of America. The Univ. Press of Kentucky, Lexington, $K y$.

${ }^{5}$ GILLETT, D. D. and I. D. KIMBROUGH. 1970. Chiropteran Mortality. Pages 262283 in About Bats, a chiropteran symposium, R. H. Slaughter and D. W. Walton (Eds.) Southern Methodist Univ. Press, Dallas, Texas.

${ }^{6}$ HAYWARD, B. and R. DAVIS. 1964. Flight speeds in western bats. J. Mammal. 45(2): 236-242. 